\title{
PENDAMPINGAN KESEHATAN MENTAL DAN RELIGI DI LEMBAGA PEMBINAAN KHUSUS ANAK (LPKA) KELAS III MATARAM
}

\section{Mental and Religious Health Assistance in Third Class of Mataram Specific Child Development Institution (LPKA)}

\author{
*Arfi Syamsun, Ida Lestari Harahap, Pujiarrohman, Lenny Herlina \\ Program Studi Pendidikan Dokter Universitas Mataram \\ Jalan Pendidikan Nomor 37 Kota Mataram, Provinsi NTB \\ *Alamat koresponednsi: arfisyamsun@gmail.com
}

(Tanggal Submission: 4 November 2020, Tanggal Accepted: 28 Desember 2020)

\begin{abstract}
ABSTRAK
Peningkatan kasus kriminalitas yang dilakukan anak-anak terus meningkat. Umumnya akibat terjebak dalam pola asosial yang menjurus pada tindakan kriminal, seperti pemerasan, narkotika, pemerkosaan, pencurian, penganiayaan dan lainnya. Demi mempertanggungjawabkan perbuatannya, anak-anak yang umumnya memiliki masalah pendidikan, kebutuhaan sosial, dan kesehatan mental, harus berhadapan dengan hukum dan tidak sedikit yang harus menjalani masa hukuman di Lembaga Pemasyaarakatan anak dengan tantangan yang berbeda dengan anak-anak yang berada di komunitas. Peningkatan pengetahuan dan kemampuan petugas LPKA dalam pendampingan Kesehatan mental penghuni binaan, serta Melakukan pendampingan khusus terkait masalah kesehatan mental penghuni guna meminimalisir terjadinya distress psikologis yang dapat mengangu kehidupan sehari-hari, kehidupan sosial bahkan ancaman kesehatan. Masalah di atas memerlukan intervensi langsung dari ahli dalam bentuk asesmen, edukasi dan pelatihan kepada petugas. Kegiatan asesmen, edukasi dan pelatihan kepada petugas dilakukan kepada warga binaan dan petugas LPKA Mataram kelas III di Desa Tojong-ojong, Desa Batu Kliang, Kabupaten Lombok Tengah menghasilkan data asesmen warga binaan dan terlaksananya edukasi tentang pendamingan kesehatan mental dengan metode konseling dan hypnosis. Berdasarkan hasil pra dan postest, disimpulkan bahwa terdapat peningkatan pengetahuan dari petugas LPKA mengenai bagaimana mendampingi penghuni binaan dalam hal Kesehatan mental, dan berdasarkan proses disimpulkan bahwa para penghuni binaan menunjukkan sikap positif setelah menjalani terapy konseling dan hypnosis.
\end{abstract}

Kata kunci : Kesehatan, pembinaan, anak 


\section{PENDAHULUAN}

Setiap tahun kasus kriminalitas yang dilakukan oleh anak-anak semakin meningkat. Ini disebabkan karena anak-anak terjebak dalam pola asosial yang makin lama dapat menjurus pada tindakan kriminal, seperti pemerasan, narkotika, pemerkosaan, pencurian, penganiayaan dan sebagainya (Waluyo, 2004). Tentu ini sangat mencemaskan dan bisa menjadi ancaman terhadap keberlangusngan generasi bangsa yang berkualitas.

Demi mempertanggungjawabkan perbuatannya, anak-anak harus berhadapan dengan hukum dan tidak sedikit yang harus menjalani masa hukuman di Lembaga Pemasyaarakatan anak. Secara umum, anakanak yang berada di Lembaga Pemasyarakatan memiliki tantangan yang berbeda dengan remaja yang berada di komunitas. Remaja yang berada di Lembaga Pemasyarakatan merupakan remaja-remaja yang terbukti melakukan kenakalan dan untuk beberapa waktu kehilangan kebebasanya. Remaja tersebut biasanya merupakan remaja yang memiliki masalah pendidikan, kebutuhaan sosial, dan kesehatan mental yang seringkali tidak diperhatikan (Scoot \& Steinberg, 2008).

Selain itu, permasalahan yang seringkali terjadi pada mereka di Lembaga Pemasyarakatan adalah bulliying dan berbagai kondisi lainnya yang tidak aman untuk remaja. Komisi perlindungan anak (KPAl) mengemukakan bahwa lebih dari separuh anak penghuni Lembaga Pemasyarakatan mengalami kekerasan atau penyiksaan dalam proses hukum yang mereka jalani (Yulnaldi, 2009).

Berdasarkan informasi di atas, maka dapat dikatakan bahwa remaja yang ada di Lembaga Pemsyarakatan rawan mendapatkan perlakukan tidak menyenangkan. $\mathrm{Hal}$ ini tentu berdampak terhadap kondisi kesehatan mental meraka. Baker \& Cunningham (dalam Stapleton dkk., 2009) menyampaikan bahwa akibat-akibat paparan kekerasan yang mungkin muncul khususnya pada remaja yaitu dapat membawa depresi dan keinginan untuk bunuh diri, kekerasan dalam berpacaran, kenakalan remaja, pelecehan dan pemggunaaan kekerasan sebagai teknik dalam mengontrol. Berdasarkan penjelasan tersebut, bisa disimpulkan bahwa remaja yang berada di bawah binaan Lembaga Pemsyarakatan rawan untuk mengalami masalah-masalah mental.

Berdasar pada masalah-masalah utama yang telah disampaikan tersebut, kegiatan pengabdian kepada masyarakat ini menawarkan solusi berupa kegiatan pendampingan kesehatan mental kepada warga binaan LPKA. Solusi yang ditawarkan diwujudkan dengan memberikan:

1. Asesmen psikologis kondisi mental warga binaan.

2. Pemberian materi tentang kesehatan mental kepada petugas

3. Pelatihan konseling dan hypnosis kepada petugas

Pendampingan kesehatan mental ini fokus pada teori dan praktik agar tujuan yang diharapkan dapat tercapai sesuai dengan target yang telah dirumuskan.

\section{METODE KEGIATAN}

Secara umum, metode yang digunakan dalam kegiatan pengabdian masyarakat ini ditentukan agar para petugas memiliki data komprehensif tentang kondisi mental para warga binaan dan memahami serta mampu mempraktekkan metode pendekatan yang tepat dalam mendampingi warga binaan. Oleh karena itu dilakukan asesmen kepada warga binaan, pelatihan konseling dan hypnosis. 
Asesmen psikologis ini dilakukan dengan cara yang menyenangkan yakni dengan cara menggambar. Menggunakan metode grafis tree atau menggambar pohon, person atau orang dan house tree person atau menggambar ketiga objek tersebut, dimana akan membuat proses asesmen menjadi lucu dan menyenangkan bagi peserta dan peserta tidak merasa ia sedang diasesmen.

Pelatihan konseling dilakukan dengan tujuan agar petugas memahami metode pendekatan serta pendampingan warga binaan yang lebih humanis yakni memandang mereka sebagai individu yang memiliki fitrah positif dan tetap memiliki peluang masa depan yang baik. Sehingga mereka dapat membantu warga binaan dalam menyadari cara berpikir yang keliru serta dampak perilaku serta emosi yang muncul dari kesalahan berpikir tersebut.

\section{HASIL DAN PEMBAHASAN}

\section{Asesmen}

Berdasarkan asesmen yang telah dilakukan maka ada beberapa informasi yang didapatkan, antara lain: (1) Belum pernah ada proses asesmen psikologis yang dilakukan kepada warga binaan; (2) Petugas-petugas belum dilatih melakukan pendampingan dengan metode yang humanis seperti metode pendampingan psikologis; (3) Petugas belum pernah mendapatkan pelatihan konseling dan hypnosis; (4) Asesmen psikologis warga binaan. Dilakukan asesmen psikologis untuk melihat kondisi kepribadian dan minat bakat warga binaan dengan menggunakan alat-alat tes psikologi.

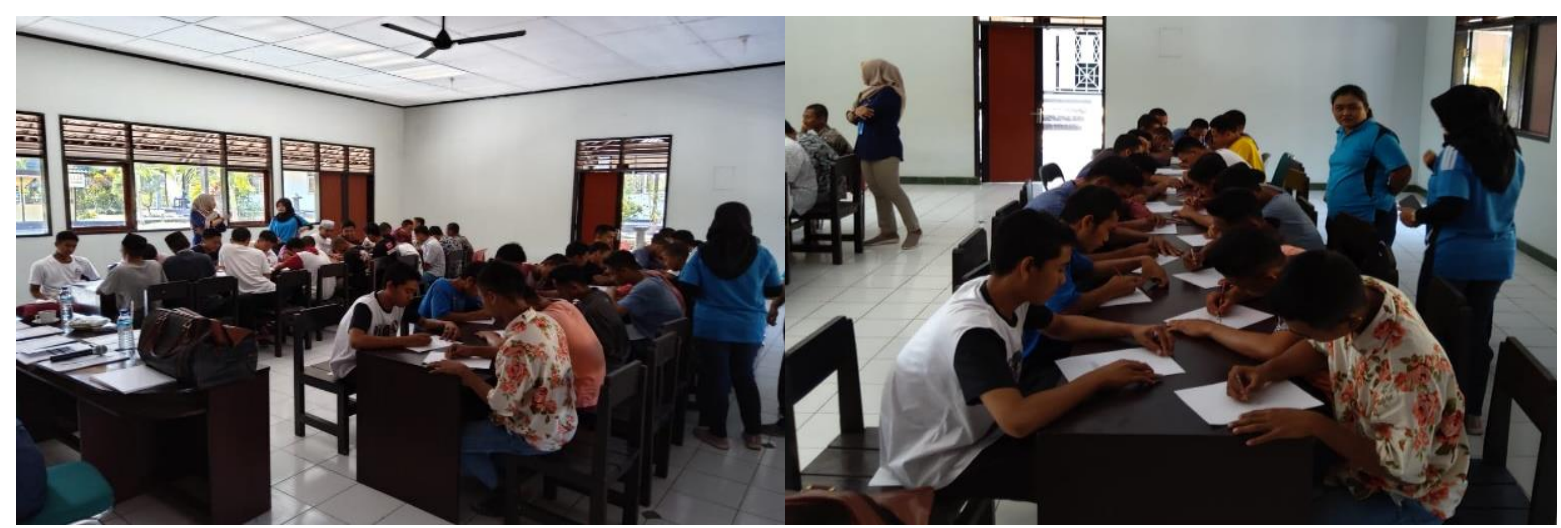

Gambar 1. Proses kegiatan asesmen

\section{Pelatihan konseling}

Pelatihan konseling dilakukan dengan tujuan agar petugas memahami metode pendekatan serta pendampingan warga binaan yang lebih humanis. Sehingga mereka dapat membantu warga binaan dalam menyadari cara berpikir yang keliruserta dampak perilaku serta emosi yang muncul dari kesalahan berpikir tersebut. Oleh karena itu warga binaan mampu dengan rela hati untuk bercerita karena petugas mampumenjalin hubungan emosi yang terapiutik.

Selain itu pelatihan hypnosis mampu memberikan gambaran metode baru kepada para petugas dalam melakukan proses asesmen sehingga mereka mendapatkan alternative cara menggali permasalahan warga binaan yang selamaini sulit untuk digali. Sehingga petugas memiliki data yang lebih mendalam terkait dengan kondisi psikologis warga binaan sesuai dengan panduan yang telah diberikan oleh negara. 


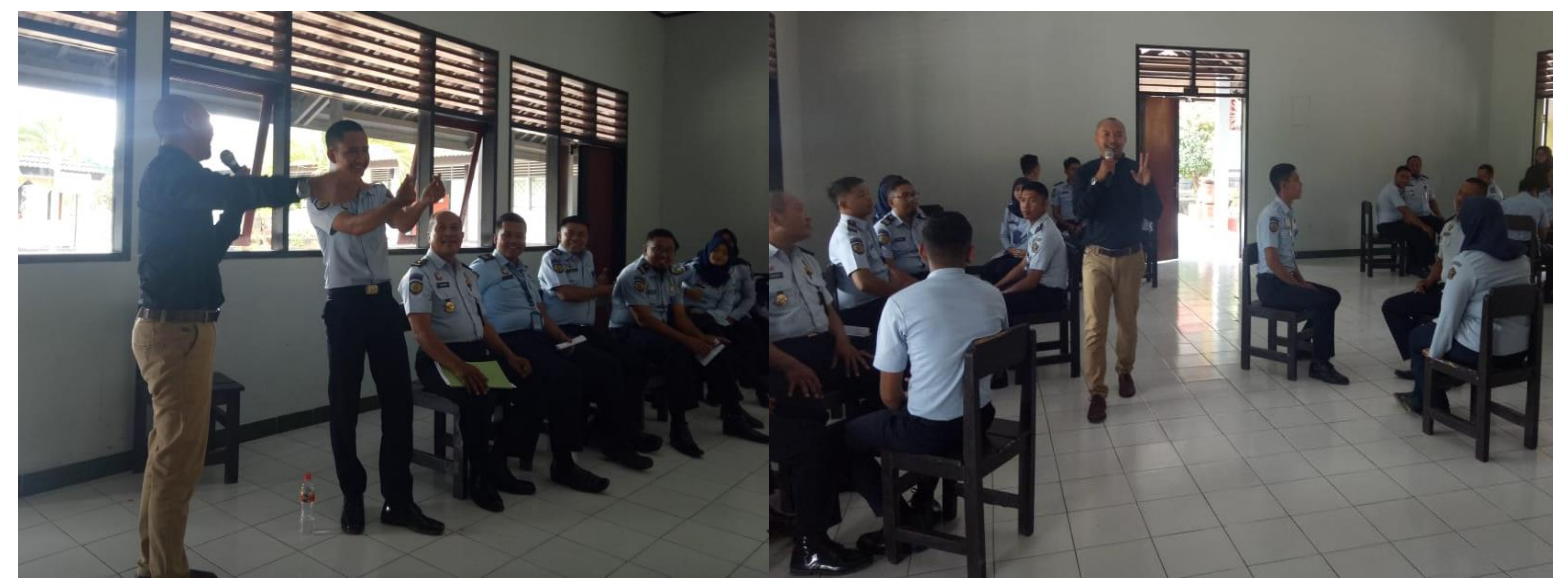

Gambar 2. Proses kegiatan Konseling

\section{Materi Konseling dan Pembinaan}

Psikologi Humanistik merupakan satu diantara beberapa aliran dalam ilmu kejiwaan atau psikologi yang muncul pada era tahun 1950-an, yang berasal dari pemikiran kalangan eksistensialisme yang berkembang pada abad pertengahan. Kehadiran psikologi humanistik muncul sebagai reaksi atas aliran psikoanalisis dan behaviorisme, sehingga dipandang sebagai "kekuatan ketiga" dalam aliran psikologi.

Psikologi humanistik atau psikologi kemanusiaan merupakan pendekatan yang multifase terhadap pengalaman dan tingkah laku manusia yang memusatkan perhatian pada keunikan dan aktualisasi diri manusia. Bagi sejumlah ahli psikologi humanistik adalah alternatif, sedangkan bagi sejumlah ahli psikologi yang lainnya merupakan pelengkap bagi penekanan tradisional behaviorisme dan psikoanalisis (Misiak dan Sexton, 2005 ). Psikologi humanistik memiliki tiga ciri utama, yaitu : 1) Psikologi humanistik menawarkan satu nilai yang baru sebagai pendekatan untuk memahami sifat dan keadaan manusia. 2) Psikologi humanistik menawarkan pengetahuan yang luas akan kaidah penyelidikan dalam bidang tingkah laku manusia. 3) Psikologi humanistik menawarkan metode yang lebih luas akan kaidah-kaidah yang lebih efektif dalam dalam pelaksanaan psikoterapi.

Pendekatan humanistik dalam konseling dilakukan dengan harapan memunculkan pemikiran dan sikap positif, seperti: 1) Mengoptimalkan kesadaran individu akan keberadaannya dan menerima keadaannya menurut apa adanya. 2) Memperbaiki dan mengubah sikap, persepsi cara berfikir, keyakinan serta pandanganpandangan individu, yang unik, yang tidak atau kurang sesuai dengan dirinya agar individu dapat mengembangkan diri dan meningkatkan self actualization seoptimal mungkin. 3) Menghilangkan hambatan-hambatan yang dirasakan dan dihayati oleh individu dalam proses aktualisasi dirinya. 4) Membantu individu dalam menemukan pilihan-pilihan bebas yang mungkin dapat dijangkau menurut kondisi dirinya.

\section{Evaluasi}

Evaluasi dilakukan pada akhir kegiatan sehingga dapat menjadi indikator dalam mengukur keberhasilan kegiatan pengabdian ini. Dalam kegiatan asesmen dan konseling dilihat sikap antusiasme para peserta dan keaktifannya dalam kegiatan konseling. Hal ini dilakukan untuk menilai kemampuan para 
peserta dalam memahami setiap materi konseling yang diberikan.

Dari seluruh proses kegiatan yang telah dilakukan secara umum peserta sangat antusias dan bersemangat dalam menerima materi konseling yang diberikan. Selama ini peserta belum pernah melakukan proses asesmen psikologis yang dilakukan kepada warga binaan. Kemudian Petugas-petugas belum dilatih melakukan pendampingan dengan metode yang humanis seperti metode pendampingan psikologis, serta petugas belum pernah mendapatkan pelatihan konseling dan hypnosis. Sehingga dengan adana kegiatan ini para peserta. Sehingga dengan adanya kegiatan ini para peserta dalam menemukan metode pendekatan dan pendampingan warga binaan yang lebih humanis. Sehingga mereka dapat membantu warga binaan dalam menyadari cara berpikir yang keliru serta dampak perilaku serta emosi yang muncul dari kesalahan berpikir tersebut. Sehingga warga binaan mampu dengan rela hati untuk bercerita dikarenakan petugas mampu menjalin hubungan emosi yang terapiutik.

\section{KESIMPULAN DAN SARAN}

Berdasarkan proses yang dilakukan sejak proses asesemen hingga intervensi ada beberapa refleksi yang disampaikan oleh Kalapas dan petugas-petugas antara lain: (1) Pelatihan ini sangat bermanfaat bagi para petugas, membantu proses petugas dalam mendampingi warga binaan yang secara usia masih tergolong-anak-anak, serta teknik-teknik yang diajarkan dalam pelatihan sesuai dengan kebutuhan di Lapas Anak. (2) warga binaan merasakan manfaat yang cukup besar terkait peningkatan rasa percaya diri dan optimisme, ditandai dengan list catatan-catatan harapan dan cita-cita masa depan sekeluar mereka dari LPKA, terutama cita-cita terkait Pendidikan.

Berdasarkan refleski tersebut ada beberapa rencana tindak lanjut yang bisa dilakukan antara lain: (1) Lapas Anak perlu membuat Data based tentang kondisi psikologis anak-anak binaan; (2) Perlu ada petugas khusus dari bidang psikologi; (3) Perlu dilakukan pelatihan-pelatihan lain untuk meningkatkan kapasitas petugas dalam menjalankan tugasnya mendapingiwarga binaan yang masih terbilang usia anak-anak.

\section{DAFTAR PUSTAKA}

Misiak dan Sexton, 2005 dalam https://nihlatul96.wordpress.com/tag/t eori-humanistik/ diunduh pada tanggal 31 Juli 2019.

Scott, E.S., \& Steinberg, L.D. (2008). Rethingking Juvenile Justice. United States: Harvard University Press https://adoc.pub/hubungan-antarapaparan-kekerasan-dan-distrespsikologis-pad.html Diakses: 20 Juli 2019 Stapleton,J. G., Kimberlly G. Philips, M. M., Wiesen-Martin, D. R. \& Beaulie, A. L. 2009. New Hampshire Endowment for Health Planning Grant Final Report: The Mnetal Health Needs OF Children Exposed to Violence in their Homes. Durhman: New Hampshire Coalition Againts Domestoic and Sexual Violance.

Waluyo, B. (2004). Pidana dan Pemidanaan. Jakarta: Sinar Grafika

Yurnaldi,2009, Separuh anak penghuni lapas alami penyiksaan. Diunduh tangal $31 \mathrm{Juli}$ 2019.http://\%20//\%20regional.kompas. com $/ \mathrm{read} / 2009 / 07 / 31 / 14354886 /$ Lebih. dari.\%20Separuh.Anak.\%20Penghuni.La pas.Alami.\%20Penyiksaan. 